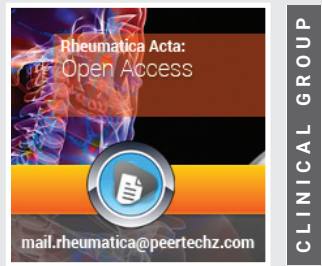

\title{
Value of ultrasound
}

\section{examination of the Leeds}

\section{Enthesitis Index in assessment} of disease activity in psoriatic arthritis

\author{
Hamada S Ahmad ${ }^{1 *}$, Sherief E Farrag1 and Osama Kombar ${ }^{2}$ \\ ${ }^{1}$ Department of Rheumatology \& Rehabilitation, Mansoura Faculty of Medicine, Mansoura University, \\ Egypt \\ ${ }^{2}$ Radiodiagnosis Department, Mansoura Faculty of Medicine, Mansoura University, Egypt
}

Received: 31 November, 2019

Accepted: 29 February, 2020

Published: 03 March, 2020

*Corresponding author: Hamada M M Sayed Ahmed Department of Rheumatology \& Rehabilitation, Mansoura Faculty of Medicine, Mansoura University, Egypt, Tel: 00966506251110;

E-mail:dr_hamada1970@yahoo.com

Keywords: Enthesitis; Leeds enthesitis index; Psoriatic arthritis; Ultrasound

https://www.peertechz.com

Check for updates

\section{Summary}

Background: Enthesitis is a major feature of psoriatic arthritis. However, clinical assessment of enthesitis is known to lack accuracy and have poor interobserver reliability.

Objective: This study aimed to determine the added value of the US assessment of enthesitis according to LEI over the clinical assessment in determination of PsA activity.

Methods: A total of 75 consecutive PsA patients diagnosed according to Classification Criteria for Psoriatic Arthritis (CASPAR criteria) participated in the study. The LEl score was used to assess the enthesitis. All PsA patients underwent US assessment by the same sonographer who was blinded to the findings of the clinical examination. Grey scale US imaging was used to assess the longitudinal and transverse planes of the 6 entheseal points of the LEl.

Results: Active PsA Patients had a significantly higher inflammation score than the PsA patients with MDA at each of the 6-LEl points. Subsequently, active PsA group has significantly higher total inflammation score than in the PsA group with MDA. On the other hand the total damage score as well as the damage score at the 6-LEl points showed insignificant difference between the two groups.

A significant correlation was identified between PASDAS with the LEl score and with the total US inflammation score. However, no significant correlation was found between the PASDAS and the total US damage score.

Conclusion: US examination of 6-LEI points is an accurate method to assess entheseal abnormalities and is significantly correlated to disease activity in PsA patients.

\section{Introduction}

Psoriatic Arthritis (PsA) is a progressive chronic inflammatory arthritis affecting approximately $30 \%$ of patients with psoriasis $[1,2]$, characterized by the affection of tendons, enthuses, joints and often results in permanent joint damage and disability [3] and impairment of quality of life [4,5].

Enthesitis is a hallmark of PsA [6,7], with estimated frequency of $30 \%$ to $50 \%$ among patients with PsA [8].
Enthesitis is a part of the CASPAR classification criteria for PsA [9]. In psoriatic arthritis, the peripheral joint and enthesitis assessment had been recognized of extreme clinical importance by the OMERACT 7 [10]. Despite that enthesitis is proposed as an indicator of disease activity and response to treatment in PsA patients, the clinical methods of determining enthesitis degree have not been typically validated for use in PsA patients [10].

The Leeds Enthesitis Index (LEI) is a clinical index that 
was designed for measuring enthesitis in PsA patients [11]. However, the specificity of clinical enthesitis count is limited since the site of most entheseal points are near to joints and can be mistaken for tender points of fibromyalgia and finding tenderness in these sites raise the possibility of false positive results [12]

Ultrasound (US) is a non-invasive tool with highly sensitivity to assess the presence of enthesitis [13]. Many US studies reported the high prevalence of subclinical enthesitis in patients with and without PsA [14-16].

However, these studies are limited by the incomplete assessment of PsA features by US with disease activity measures routinely used in RA [17]. This study aimed to determine the added value of the US assessment of enthesitis according to LEI over the clinical assessment in determination of PsA activity.

\section{Subjects and methods}

\section{Subjects}

A total of 75 consecutive PsA patients diagnosed according to Classification Criteria for Psoriatic Arthritis (CASPAR criteria) [9], participated in the study. Patients were collected from the outpatient clinic of Rheumatology, in Saudi Arabia, during routine visit to the clinic. The protocol for this study was approved by the Institutional Research Board \& the Ethical Committee.

Exclusion criteria for cases were rheumatoid arthritis, crystal induced arthritis, osteoarthritis, other seronegative spondyloarhrpathies and other active inflammatory skin conditions. All patients were instructed to stop taking NSAIDs for at least 24 hours prior to assessments, to avoid the immediate masking effect of these medications. Prior to inclusion, the aim and the study procedures were explained to all participants who signed consent. This study was approved by the local ethics committee.

\section{Clinical assessment}

Patients were clinically assessed through full history taking in addition to both general and local examinations as well as review of their medical records. The LEI score was used to assess the enthesitis. Enthesitis was defined as tenderness at the enthesis site by applying pressure of around $4 \mathrm{~kg} / \mathrm{cm}^{2}$ (required to blanch the tip of fingernail of the examiner). LEI consists of assessment of tenderness at 6 sites: insertion of bilateral Achilles tendon, medial femoral condyles, and lateral humeral epicondyles. Tenderness at each site is measured on a dichotomous basis: o (not tender) and 1 (tender) [11]

PASDAS is a composite disease activity measurement for the psoriatic arthritis and it is based on patient (PtGA) and physician (PhGA) global VAS scores, tender (SJC66) and swollen (SJC68) joint counts, dactylitis and enthesitis, Physical Component Summary (PCS) scale of the Short Form 36 (SF36), and CRP level [18]. In the current study, Minimal Disease Activity (MDA) on the PASDAS was a score of $<1.9$ [19].

\section{Laboratory assessment}

Laboratory assessments including Erythrocyte Sedimentation Rate (ESR), complete blood cell count, and C-reactive protein (CRP) levels were done. Also, Rheumatoid Factor (RF) titers were determined. ESR was measured by the standard Westergren method $(\mathrm{mm} / \mathrm{h})$. CRP levels were measured by standard nephelometry $(\mathrm{mg} / \mathrm{l})$. RF was measured by Enzyme-Linked Immunosorbent Assay (ELISA) and results are expressed in titers of $1 / 40$ and higher.

\section{US assessment}

All PsA patients underwent US assessment by the same sonographer who was blinded to the findings of the clinical examination. All US scans were performed on the same day as the clinical examination. US examinations were carried out using The LOGIQ* P6 Ultrasound Machine (General Electric Company, GE health care, USA) using a 8-13 $\mathrm{MHz}$ linear transducer.

The sonographic assessments were done at each enthesis sites of the LEI. Tendon scanning was done in the longitudinal and transverse planes. The common extensor origins of the humerus was evaluated while the patient is seated with slightly flexed elbows, hand are resting on the knee and the forearm in internal rotation. The medial collateral ligament insertion into the femur was examined with the patient supine and the knee flexed at $70^{\circ}$. The tendo-Achilles insertion was examined with the patient in prone position, with the feet hanged over the couch edge with the ankle in neutral position [12].

Grey scale US imaging was used to assess the longitudinal and transverse planes of the 6 entheseal points of the LEI for the occurrence of: (1) Erosion - identified by presence of a step-down cortical contour defect observed in 2 planes and with diameter > 2mm; (2) Enthesophyte - identified by presence of bony step-up prominence at the end of a normal bone contour with formation of a bony spur within the enthesis tendinous portion;

(3) Bursitis - defined as a localized, well-delineated hypoechoic area at the site of an anatomical bursa which was compressible (indicating presence of fluid); (4) Entheseal thickening - defined as a discrepancy at the contralateral enthesis thickness or if there is bulky appearance of the normally smooth entheseal contour and (5) Peri-entheseal soft tissue edema - defined as a compressible fluid on the outer margin of the enthesis. In addition, power Doppler US was used to assessthe presence of neovascularization in the longitudinal and transverse plains just adjacent to the entheseal insertion. The scoring of all US findings were either absent (score 0 ) or present (score 1) [20].

The US findings were combined into 2 scores as follows: (1) Inflammation score involves the sum of 4 items of vascularization, edema, bursitis and entheseal thickening (score range $0-4$ ) and (2) damage score involves the sum of 2 items of erosion and enthesophyte (score range $0-2$ ) [20]. 

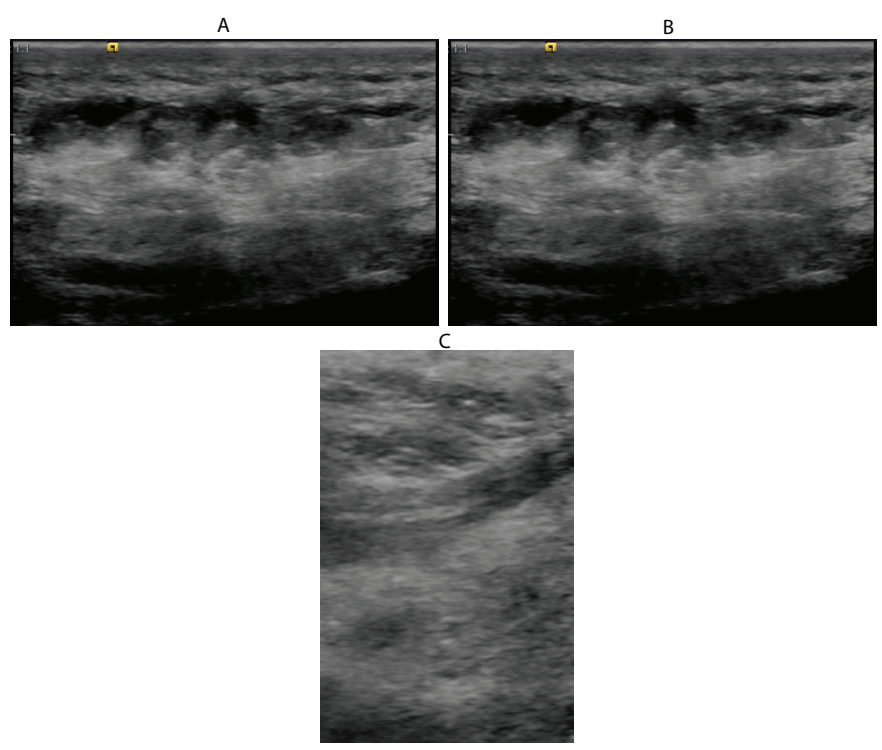

39 years old female patient with psoriasis presented with pain at the right heel.

\section{Ultrasound examination shows:}

\section{Marked oedema of the subcutaneous tissue.}

Peritendinous oedema along the course of the planter flexor tendon.

Thickening and oedema within and around insertion of the. planter flexor tendon.
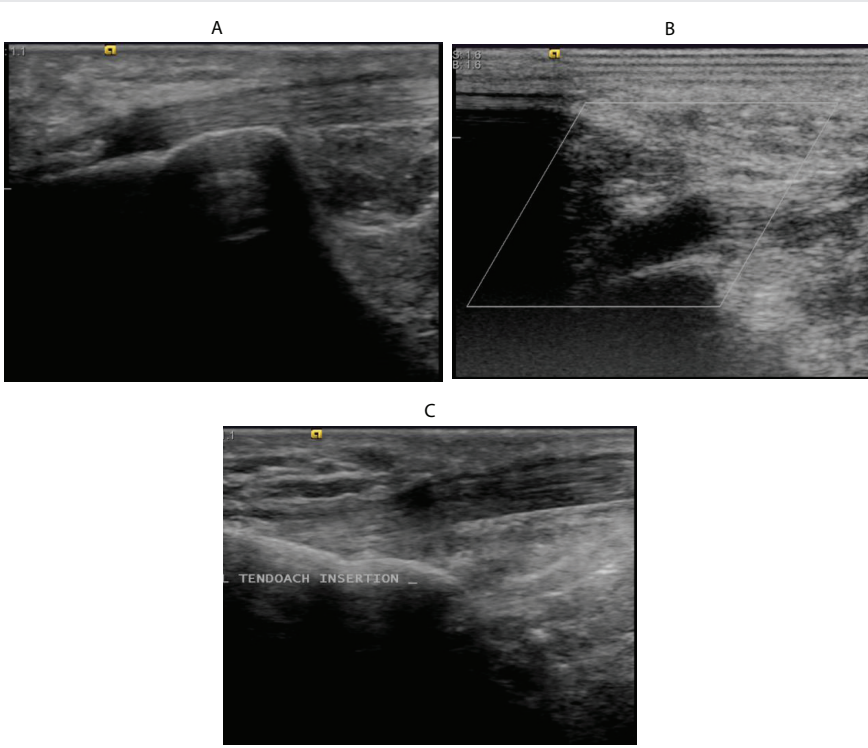

59 years old female patient with psoriasis presented with pain at the right tendoachilis insertion.

\section{Ultrasound examination shows:}

A. Enthesophyte and Perientheseal soft tissue oedema.

B. Bursitis at insertion of tendoachilis tedon into calcaneum.
C. Healthy left tendoachilis tendon insertion, for comparison, yet mild erosions at its insertion noted.

\section{Statistical analysis}

Data were analyzed using the SPSS v.20.0. Variables with continuous data expressed as mean \pm SD while variables with categorical data expressed as number and percent. Variable with continuous data compared using the independent sample Student's t test while Variable with categorical data compared using the chi square test. Correlations were performed using the correlation co-efficient test. ROC curve analysis was used to assess the ability of the total US inflammation score in discrimination of patients with active PsA. Significance was set at $\mathrm{p}$ value of $<0.05$.

\section{Results}

75 patients were included in this study with PsA, 41 (54.7\%) had an active PsA while 34 (45.3\%) had an MDA PsA (Figure 1). Table 1 demonstrates the comparison of the demographic, clinical and laboratory data are compared between active PsA patients and PsA patients with MDA. PASDAS and its individual components were all significantly higher in the active PsA group Active PsA group has significantly higher LEI score than in the PsA group with MDA. In addition, active PsA group has significantly higher ESR and CRP.

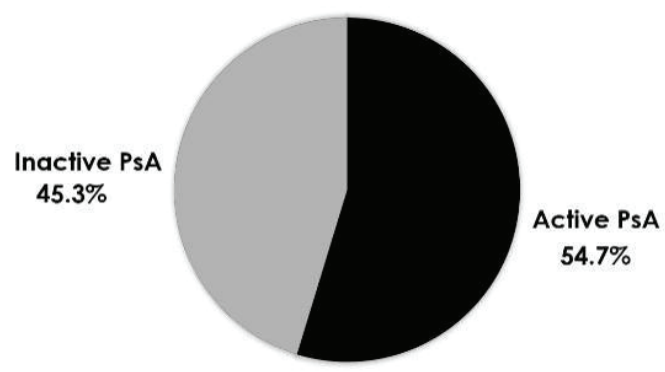

Figure 1: Distribution of patients with active PsA and PsA patients with MDA.

\section{Frequency of entheses abnormalities in clinical versus US examination in the 6 -LEI points}

Of the 450 entheses in the 75 patients examined clinically, a total of 170 entheses were tender in 63 patients while 12 patients had no tender enthuses. The entheses with most frequent tenderness was the Achilles tendon (97 tendons in 61 patients), followed by medial collateral ligament insertion tenderness ( 46 ligaments in 33 patients), while it was least in the common extensor origins of the humerus (27 tendons in 24 patients). In US examination of same enthuses sites, abnormalities were found in 306 entheses with a total of 306 enthese with the Achilles tendon most frequently involved (112 tendons in 66 patients) and the medial collateral ligament insertion tenderness comes second (53 ligaments in 36 patients) and lastly the common extensor origins of the humerus ( 31 tendons in 27 patients). Only two patient had no enthesis abnormailites in US examination. 


\section{US findings}

The US findings at the 6-LEI points are compared between active PsA patients and PsA patients with MDA and demonstrated in Table 2. Active PsA Patients had a significantly higher inflammation score than the PsA patients with MDA at each of the 6-LEI points. Subsequently, active PsA group has significantly higher total inflammation score than in the PsA group with MDA (16.6 \pm 4.7 vs $13.1 \pm 5.6$ respectively, $\mathrm{p}=0.005)$. On the other hand the total damage score as well as the damage score at the 6-LEI points showed insignificant difference between the two groups.

A significant correlation was identified between PASDAS with the LEI score $(\mathrm{r}=0.280, \mathrm{p}=0.015)$ (Figure 2) and with the total US inflammation score $(\mathrm{r}=0.332, \mathrm{p}=0.004)$ (Figure 3 ). However, no significant correlation was found between the PASDAS and the total US damage score $(r=0.007, p=0.951)$.

\section{ROC curve analysis}

The analysis of ROC curve revealed that the total US inflammation score $>10$ at the 6-LEI points can differentiate patients with active from those with MDA PsA (AUC=0.717) (Figure 4). As shown in Table 3, at this point the total US inflammation score at the 6-LEI points has a sensitivity of 0.951 , specificity of 0.706 , positive predictive value of 0.796 and negative predictive value of 0.923 and accuracy of 0.840 .

Table 1: Comparison of the demographic, clinical and laboratory findings between patients with active PsA and PsA patients with MDA.

\begin{tabular}{|c|c|c|c|c|c|}
\hline \multirow[b]{3}{*}{ Age (years) } & \multicolumn{2}{|c|}{$\begin{array}{c}\text { Active PsA } \\
(n=41)\end{array}$} & \multirow{2}{*}{\multicolumn{2}{|c|}{$\begin{array}{c}\text { PsA patients } \\
\text { with MDA } \\
(n=34)\end{array}$}} & \multirow[b]{3}{*}{0.571} \\
\hline & \multirow[b]{2}{*}{49.2} & \multirow[b]{2}{*}{ \pm 16.4} & & & \\
\hline & & & 46.9 & \pm 17.5 & \\
\hline Sex, male $(n, \%)$ & \multicolumn{2}{|c|}{$22,53.7 \%$} & \multicolumn{2}{|c|}{$19,55.9 \%$} & 0.847 \\
\hline Duration of psoriasis (years) & 10.7 & \pm 3.4 & 10.3 & \pm 3.2 & 0.638 \\
\hline Duration of PsA (years) & 5.0 & \pm 2.6 & & \pm 2.4 & 0.787 \\
\hline BMI $\left(\mathrm{kg} / \mathrm{m}^{2}\right)$ & 29.0 & \pm 4.1 & 30.2 & \pm 4.3 & 0.236 \\
\hline \multicolumn{6}{|l|}{ Arthritis } \\
\hline Bach pain $(n, \%)$ & \multicolumn{2}{|c|}{$12,29.3 \%$} & \multicolumn{2}{|c|}{$8,23.5 \%$} & 0.576 \\
\hline Oligo-arthritis $(\mathrm{n}, \%)$ & \multicolumn{2}{|c|}{$25,61.0 \%$} & \multicolumn{2}{|c|}{$21,61.8 \%$} & 0.944 \\
\hline Poly-arthritis & \multicolumn{2}{|c|}{$15,36.6 \%$} & \multicolumn{2}{|c|}{$11,32.4 \%$} & 0.701 \\
\hline Patient global VAS scores & 40.1 & \pm 12.1 & 34.4 & \pm 10.6 & 0.032 \\
\hline Physician global VAS scores & 30.7 & \pm 10.8 & 24.5 & \pm 10.8 & 0.034 \\
\hline Tender joint count- 66 & 39.8 & \pm 14.7 & 27.4 & \pm 13.3 & $<0.001$ \\
\hline Swollen joint count-68 & 31.1 & \pm 9.7 & 21.6 & \pm 10.7 & $<0.001$ \\
\hline Dactylitis count & \multicolumn{2}{|c|}{$5.5 \pm 1.4$} & \multicolumn{2}{|c|}{$4.1 \pm 1.8$} & 0.014 \\
\hline Physical component of SF-36 & 34.8 & \pm 14.9 & 23.8 & \pm 10.5 & $<0.001$ \\
\hline PASDAS & \multicolumn{2}{|c|}{$3.7 \pm 1.0$} & \multicolumn{2}{|c|}{$1.1 \pm 0.4$} & $<0.001$ \\
\hline Leeds Enthesitis Index & \multicolumn{2}{|c|}{$3.0 \pm 1.4$} & \multicolumn{2}{|c|}{$1.4 \pm 1.2$} & $<0.001$ \\
\hline $\operatorname{ESR}(\mathrm{mm})$ & 38.8 & \pm 14.2 & 31.2 & \pm 10.5 & 0.013 \\
\hline $\mathrm{CRP}(\mathrm{mg} / \mathrm{dl})$ & 22.9 & \pm 10.4 & 18.2 & \pm 8.4 & 0.036 \\
\hline Methotrexate (n, \%) & \multicolumn{2}{|c|}{$34,82.9 \%$} & \multicolumn{2}{|c|}{$24,70.6 \%$} & 0.204 \\
\hline Anti-tumor necrosis factor (n, \%) & \multicolumn{2}{|c|}{$11,26.8 \%$} & \multicolumn{2}{|c|}{$13,38.2 \%$} & 0.292 \\
\hline
\end{tabular}

Table 2: Comparison of the US findings at the 6-LEI points between patients with active PsA and patients with PsA patients with MDA.

\begin{tabular}{|c|c|c|c|}
\hline & $\begin{array}{c}\text { Active PsA } \\
(n=41)\end{array}$ & $\begin{array}{c}\text { PsA patients with } \\
\text { MDA }\end{array}$ & $\mathbf{p}$ \\
\hline & & $(n=34)$ & \\
\hline \multicolumn{4}{|l|}{ Inflammation score } \\
\hline $\begin{array}{l}\text { Right humeral lateral } \\
\text { epicondyle }\end{array}$ & $2.8 \pm 1.0$ & $2.3 \pm 1.2$ & 0.040 \\
\hline $\begin{array}{l}\text { Left humeral lateral } \\
\text { epicondyle }\end{array}$ & $2.4 \pm 1.1$ & $1.9 \pm 0.9$ & 0.017 \\
\hline Right knee median condyle & $2.7 \pm 1.1$ & $2.2 \pm 1.1$ & 0.037 \\
\hline Left knee median condyle & $2.8 \pm 1.2$ & $2.1 \pm 1.1$ & 0.019 \\
\hline $\begin{array}{l}\text { Right Achilles tendon } \\
\text { insertion }\end{array}$ & $2.9 \pm 1.2$ & $2.3 \pm 1.1$ & 0.034 \\
\hline $\begin{array}{l}\text { Left Achilles tendon } \\
\text { insertion }\end{array}$ & $2.9 \pm 1.1$ & $2.4 \pm 1.2$ & 0.040 \\
\hline Total US inflammation score & $16.6 \pm 4.7$ & $13.1 \pm 5.6$ & 0.005 \\
\hline \multicolumn{4}{|l|}{ Damage score } \\
\hline $\begin{array}{l}\text { Right humeral lateral } \\
\text { epicondyle }\end{array}$ & $0.9 \pm 0.8$ & $1.2 \pm 0.8$ & 0.187 \\
\hline $\begin{array}{l}\text { Left humeral lateral } \\
\text { epicondyle }\end{array}$ & $1.0 \pm 0.9$ & $0.8 \pm 0.7$ & 0.168 \\
\hline Right knee median condyle & $0.8 \pm 0.8$ & $0.9 \pm 0.8$ & 0.744 \\
\hline Left knee median condyle & $1.0 \pm 0.8$ & $1.1 \pm 0.9$ & 0.958 \\
\hline $\begin{array}{l}\text { Right Achilles tendon } \\
\text { insertion }\end{array}$ & $1.2 \pm 0.9$ & $0.9 \pm 0.7$ & 0.119 \\
\hline $\begin{array}{l}\text { Left Achilles tendon } \\
\text { insertion }\end{array}$ & $1.1 \pm 0.8$ & $0.9 \pm 0.8$ & 0.469 \\
\hline Total damage score & $6.1 \pm 2.3$ & $5.8 \pm 1.4$ & 0.440 \\
\hline
\end{tabular}

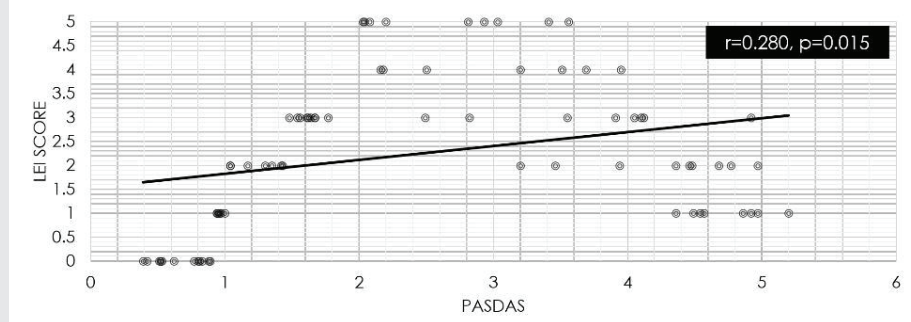

Figure 2: The correlation between the Leeds, Enthesitis Index (LEI) score and the Psoriatic Arthritis Disease Activity Score (PASDAS)

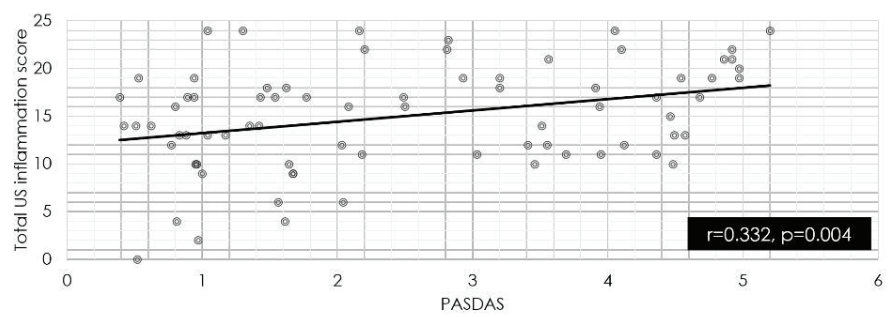

Figure 3: The correlation between the total US inflammation score and the Psoriatic Arthritis Disease Activity Score (PASDAS)

\section{Discussion}

The limitations of the clinical examination to assess the entheses in the PsA had encouraged the importance of US for entheses abnormalities detection of in PsA patients. US is increasingly used in PsA and provided additional clues regarding the severity and the pathogenesis of PsA. Currently,

Citation: Ahmad HS, Farrag SE, Kombar O (2020) Value of ultrasound examination of the Leeds Enthesitis Index in assessment of disease activity in psoriatic arthritis. Rheumatica Acta: Open Access 4(1): 001-006. DOI: httpa://dx.doi.org/10.17352/raoa.000011 


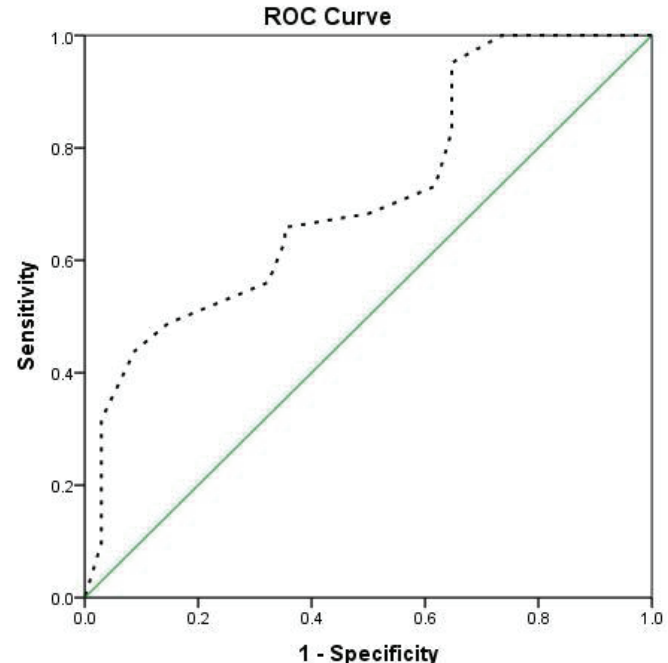

Figure 4: ROC curve for the discriminatory ability of the total US inflammation score at the 6-LEl points between MDA and active PsA patients (AUC $=0.717$ ).

Table 3: The diagnostic value of the total US inflammation score and the Psoriatic Arthritis Disease Activity Score (PASDAS) at value $>10.0$.

\begin{tabular}{|c|c|c|}
\hline & Value & $95 \% \mathbf{C I}$ \\
\hline Sensitivity & 0.951 & $0.835-0.994$ \\
\hline Specificity & 0.706 & $0.525-0.849$ \\
\hline Positive predictive value & 0.796 & $0.698-0.868$ \\
\hline Negative predictive value & 0.923 & $0.753-0.979$ \\
\hline Accurac & 0.840 & $0.737-0.915$ \\
\hline
\end{tabular}

many composite measures of disease activity in PsA were in use; however, PASDAS has a better ability to identify patients with MDA from those with higher disease activity [18].

Enthesitis is common feature in PsA [21]. In the present study, the 6-LEI points were examined clinically and by US in the same day. Clinical examination had revealed $170 / 450$ entheses tender locations, meanwhile 306/450 entheses abnormalities were detected by US examination. These findings indicate that 136 locations had subclinical enthesitis.

Previous studies revealed significant discrepancy of inflammation between US and clinical findings in rheumatic diseases $[22,23]$ which is in keeping with our results.. Subclinical Sonographic enthesitis prevalence in PsA patients and in patients with psoriasis without arthropathy was high in many previous studies [14-16]. De Filippis et al. [24], found entheseal abnormalities in $25 \%$ of the psoriasis patients detected by US and not by clinical examination. Also in agreement with the findings of the present study, Acquacalda et al., found US enthesitis in $25.9 \%$ of the psoriasis patients without musculoskeletal symptoms.

In the present study, the most common site of entheseal involvement was the Achillis tendon. Similar finding was reported by Galluzzo et al., [25], who found that $71 \%$ of the PsA patients had US features of tendon involvement with the Achilles tendon is the most frequent sites of enthesopathic involvement in PsA (11 tendons in 6 patients), producing heel pain, and difficulty walking. Similarly, D’Agostino et al., [26], found that the most frequent site of enthesopathy in PsA is the Achilles tendon.

Perrotta et al., [27], reported that PDUS detected structural and inflammatory abnormalities of enthesis in early PsA patients. However, in the current study, in agreement with results of study of Ahmed et al., [28], no PDUS entheseal signals were detected in PsA patients.

In the current study, PASDAS is significantly correlated with clinical LEI score in PsA patients and strongly correlated with the total US inflammation score at the 6-LEI points ( $\mathrm{p}=0.015$ and $\mathrm{p}=0.004$ respectively). Ahmed et al. [28], reported a direct significant correlation between PASDAS score and the clinical LEI score in active PsA patients. Similar findings were reported by the study of Girolomoni and Gisondi [29], who reported that patients with severe clinical psoriasis outcome had a significantly higher US score (measured by Glasgow Ultrasound Enthesitis Scoring System) and is correlated with higher disease activity. Moreover, Aydin et al., [30], reported that psoriatic patients (with or without arthritis) had shown higher inflammation-related enthesopathy scores and the PsA patients had higher US enthesopathy scores than psoriatic patients with arthritis.

However, Ash et al., [31], found no link between the severity of psoriasis and enthesitis was evident. The discrepancy could be explained by the fact that Ash et al. enrolled psoriatic patients with nail changes but with no evident arthritis.

Although the mechanism of enthesitis in PsA still not fully understood, the roles of environmental, mechanical stress, immunologic and genetic factors were proposed. Gisondi et al., [14], proposed the role of increased mechanical stress on the entheses of the lower limbs as a cause of enthesitis particularly in obesity which is also associated with increased levels of pro-inflammatory cytokines and systemic inflammation. McGonagle et al., [32], also suggested that enthesitis arises at sites of compression and high shear forces, resulting from an interaction between micro-trauma, mechanical stress, and variably in mechanisms of tissue repair leading to inflammation.

In the present study, ROC curve analysis showed that the total US inflammation score $>10$ at the 6 -LEI points can decimate patients with active from those with MDA PsA patients (AUC=0.717) with good accuracy. Future studies can assess the validity of this score in the detection of the PsA patients with active disease at this cut-off point or can generate more accurate cut-off point in studies with lager PsA population.

\section{Conclusion}

US examination of 6-LEI points is an accurate method to assess entheseal abnormalities and is significantly correlated to disease activity in PsA patients.

https://www.hindawi.com/journals/isrn/2011/731917/

https://www.ncbi.nlm.nih.gov/pmc/articles/PMC5558768/ full.pdf

https://www.rheumatologie.at/pdf/annrheumdis-2012-203073. 


\section{References}

1. Haroon M, Kirby B, Fitz Gerald O (2013) High prevalence of psoriatic arthritis in patients with severe psoriasis with suboptimal performance of screening questionnaires. Ann Rheum Dis 72: 736-740. Link: http://bit.ly/2TeDkz6

2. Ogdie A, Langan S, Love T, Haynes K, Shin D, et al. (2013) Prevalence and treatment patterns of psoriatic arthritis in the UK. Rheumatology (Oxford) 52 : 568-575. Link: http://bit.ly/3anMKO7

3. Gladman DD, Stafford-Brady F, Chang CH, Lewandowski K, Russell ML (1990) Longitudinal study of clinical and radiological progression in psoriatic arthritis. J Rheumatol 17: 809-812. Link: http://bit.ly/2TycVex

4. Husted JA, Gladman DD, Farewell VT, Cook RJ (2001) Health-related quality of life of patients with psoriatic arthritis: a comparison with patients with rheumatoid arthritis. J Arthritis Rheum 45: 151-158. Link: http://bit.ly/2VAT40L

5. Leung YY, Tam LS, Kun EW, Li EK (2008) Impact of illness and variables associated with functional impairment in Chinese patients with psoriatic arthritis. Clin Exp Rheumatol 26: 820-826. Link: http://bit.ly/3cq3gPs

6. Ranza R, Carneiro S, Qureshi AA, Martins G, Rodrigues JJ, et al. (2015) Prevalence of psoriatic arthritis in a large cohort of Brazilian patients with psoriasis. J Rheumatol 42: 829-834. Link: http://bit.ly/2wnWOba

7. Polachek A, Li S, Chandran V, Gladman DD (2017) Clinical Enthesitis in a Prospective Longitudinal Psoriatic Arthritis Cohort: Incidence, Prevalence, Characteristics, and Outcome. Arthritis Care Res (Hoboken) 69: 1685-1691. Link: http://bit.ly/387UORO

8. Gladman DD, Chandran V (2011) Observational cohort studies: lessons learnt from the University of Toronto Psoriatic Arthritis Program. Rheumatology (Oxford) 50: 25-31. Link: http://bit.ly/38g3upk

9. Taylor W, Gladman D, Helliwell P, Marchesoni A, Mease P, et al. (2006) Classification criteria for psoriatic arthritis: development of new criteria from a large international study. Arthritis Rheum 54: 2665-2673. Link: http://bit.ly/2vuBAsh

10. Gladman DD, Strand V, Mease PJ, Antoni C, Nash P, et al. (2005) OMERACT 7 psoriatic arthritis workshop: synopsis. Ann Rheum Dis 64 Suppl 2: ii115-116. Link: http://bit.ly/3ao2CQZ

11. Healy PJ, Helliwell PS (2008) Measuring clinical enthesitis in psoriatic arthritis: assessment of existing measures and development of an instrument specific to psoriatic arthritis. Arthritis Rheum 59: 686-691. Link: http://bit.ly/2uJwQyy

12. Kristensen S, Christensen JH, Schmidt EB, Olesen JL, et al. (2016) Assessment of enthesitis in patients with psoriatic arthritis using clinical examination and ultrasound. Muscles Ligaments and Tendons J 6: 241-247. Link: http://bit.ly/2TvkSB6

13. Gandjbakhch F, Terslev L, Joshua F, Wakefield RJ, Naredo E, et al. (2011) Ultrasound in the evaluation of enthesitis: status and perspectives. Arthritis Res Ther 13: R188. Link: http://bit.ly/2VAsJ2N

14. Gisondi P, Tinazzi I, El-Dalati G, Gallo M, Biasi D, et al. (2008) Lower limb enthesopathy in patients with psoriasis without clinical signs of arthropathy: a hospital-based case-control study. Ann Rheum Dis 67: 26-30. Link: http://bit.ly/2wpdjur

15. Gutierrez M, Filippucci E, De Angelis R, Salaffi F, Filosa G, et al. (2011) Subclinical entheseal involvement in patients with psoriasis: an ultrasound study. Semin Arthritis Rheum 40: 407-412. Link: http://bit.ly/2vuzTuT

16. Naredo E, Möller I, de Miguel E, Batlle-Gualda E, Acebes C, et al. (2011) High prevalence of ultrasonographic synovitis and enthesopathy in patients with psoriasis without psoriatic arthritis: a prospective case-control study Rheumatology 50: 1838-1848. Link: http://bit.ly/2Tt0lx0

17. Husic R, Gretler J, Felber A, Graninger WB, Duftner C, et al. (2014) Disparity between ultrasound and clinical findings in psoriatic arthritis. Ann Rheum Dis 73: 1529-1536. Link: http://bit.ly/2TvBcl7

18. Helliwell PS, FitzGerald O, Fransen J, Gladman DD, Kreuger GG, et al. (2013) The development of candidate composite disease activity and responder indices for psoriatic arthritis (GRACE project). Ann Rheum Dis 72: 986-991. Link: http://bit.ly/3akNUdw

19. Coates LC, Helliwell PS (2016) Defining Low Disease Activity States in Psoriatic Arthritis using Novel Composite Disease Instruments. J Rheumatol 43: 371-375. Link: http://bit.ly/38ejrMH

20. Ibrahim G, Groves C, Chandramohan M, Beltran A, Valle R, Reyes B, et al. (2011) Clinical and ultrasound examination of the leeds enthesitis index in psoriatic arthritis and rheumatoid arthritis. SRN Rheumatol 2011: 731917. Link: http://bit.ly/3cjF8hA

21. Kavanaugh A, Cassell S (2005) The assessment of disease activity and outcomes in psoriatic arthritis. Clin Exp Rheumatol 23: S142-S147. Link: http://bit.ly/2I6YTv0

22. Schirmer M, Duftner C, Schmidt WA, Dejaco C (2011) Ultrasonography in inflammatory rheumatic disease: an overview. Nat Rev Rheumatol 7: 479-488. Link: http://bit.ly/3cmtiDp

23. Dejaco C, Duftner C, Schirmer M (2012) Expectations of rheumatologists on imaging results. Radiologe 52: 110-115. Link: http://bit.ly/2VC5xBa

24. De Filippis LG, Caliri A, Lo Gullo R, Bartolone S, Miceli G, et al. (2005) Ultrasonography in the early diagnosis of psoriasis-associated enthesopathy. Int J Tissue React 27: 159-162. Link: http://bit.ly/2VAvEZj

25. Galluzzo E, Lischi DM, Taglione E, Lombardini F, Pasero G, et al. (2000) Sonographic analysis of the ankle in patients with psoriatic arthritis. Scand $J$ Rheumatol 29: 52-55. Link: http://bit.ly/3akPP1D

26. D’Agostino MA, Said-Nahal R, Hacquard-Bouder C, Brasseur JL, Dougados M et al. (2003) Assessment of peripheral enthesitis in the spondylarthropathies by ultrasonography combined with power Doppler: a cross-sectional study. Arthritis Rheum 48: 523-533. Link: http://bit.ly/3cmH0pU

27. Perrotta FM, Astorri D, Zappia M, Reginelli A, Brunese L, et al. (2016) An ultrasonographic study of enthesis in early psoriatic arthritis patients naive to traditional and biologic DMARDs treatment. Rheumatol Int 36: 1579-1583. Link: http://bit.ly/2TdruF5

28. Ahmed MM, Elolemy GG, Alfeeli AK, Baqer AB, Gad AM (2017) Ultrasonographic Enthesopathy and Disease Activity in Psoriatic Arthritis. Open Access Maced J Med Sci 5: 651-656. Link: http://bit.ly/39r2Fes

29. Girolomoni G, Gisondi P (2009) Psoriasis and systemic inflammation: underdiagnosed enthesopathy. J Eur Acad Dermatol Venereol 23 Suppl 1: 3-8. Link: http://bit.ly/38dymXm

30. Aydin SZ, Ash ZR, Tinazzi I, Castillo-Gallego C, Kwok C, et al. (2013) The link between enthesitis and arthritis in psoriatic arthritis: a switch to a vascula phenotype at insertions may play a role in arthritis development. Ann Rheum Dis 72: 992-995. Link: http://bit.ly/2wTNeNB

31. Ash ZR, Tinazzi I, Gallego CC, Kwok C, Wilson C, et al. (2012) Psoriasis patients with nail disease have a greater magnitude of underlying systemic subclinical enthesopathy than those with normal nails. Ann Rheum Dis 71: 553-556. Link: http://bit.ly/2vmvmuF

32. McGonagle D, Stockwin L, Isaacs J, Emery P (2001) An enthesitis based mode for the pathogenesis of spondyloarthropathy: additive effects of microbial adjuvant and biomechanical factors at disease sites. J Rheumatol 28: 2155 2159. Link: http://bit.ly/3cjlhxU

Copyright: (c) 2020 Ahmad HS, et al. This is an open-access article distributed under the terms of the Creative Commons Attribution License, which permits unrestricted use, distribution, and reproduction in any medium, provided the original author and source are credited.

Citation: Ahmad HS, Farrag SE, Kombar O (2020) Value of ultrasound examination of the Leeds Enthesitis Index in assessment of disease activity in psoriatic arthritis. Rheumatica Acta: Open Access 4(1): 001-006. DOI: httpa://dx.doi.org/10.17352/raoa.000011 